\title{
Cognitive stimulation program mediated by digital inclusion and walking practice
}

\begin{abstract}
This study aimed to present the method of the cognitive stimulation program based on digital inclusion and walking practice, at the University of Cruz Alta. The project has already served approximately 210 people 60 years of age or older. The program takes place along with the university semester of the University, with weekly meetings of approximately 90 minutes, totaling 16 semester meetings. The elderly use computers for 45 minutes and then walk for the same time. In the first and last semester meetings sociodemographic, health and behavioral variables, cognitive performance, functional capacity and six-minute walk test were collected. The project was implemented in 2011 only with the use of computers and the practice of walking in conjunction with the use of computers in 2018. Such programs of extreme importance owe to the high rate of elderly people with cognitive problems, digitally excluded and physically inactive.
\end{abstract}

Keywords: elderly, motor activity, use of computers, loss of autonomy, functional independence
Volume 9 Issue 4 - 2019

\author{
Rodrigo de Rosso Krug,' Lucas Wibelinger \\ de Campos, ${ }^{2}$ Leonardo Henrique da Silva,' \\ Juliedy Waldow Kupske,' Patrícia Mariotto \\ Mozzaquatro Chicon, ${ }^{3}$ Moane Marchesan ${ }^{4}$ \\ 'Post Graduate Program in Integral Health Care, University of \\ Cruz Alta, Brazil \\ ${ }^{2}$ Physical Education Course, University of Cruz Alta, Brazil \\ ${ }^{3}$ Computation Sciences Course, University of Cruz Alta, Brazil \\ ${ }^{4}$ Multiprofessional Residence in Family Health, Regional \\ University of the Northwest of the State of Rio Grande do Sul, \\ Brazil
}

Correspondence: Rodrigo de Rosso Krug, Post Graduate Program in Integral Health Care, University of Cruz Alta, Brazil, Email rodrigo_krug@hotmail.com

Received: July 10, 2019 | Published: July 31, 2019

\section{Introduction}

Global population aging is occurring rapidly due to declining fertility and mortality rates, advances in health and improved basic sanitation. This process of human aging causes declines in the physical and functional abilities of the organism, increase in the number of diseases, decrease in self-esteem, socialization ${ }^{1}$ and increased cognitive problems. ${ }^{1-3}$

Cognitive problems can lead to a significant impairment of memory, learning, language, orientation and executive functions, speed of information processing, loss of autonomy, functional independence, quality of life and worsening of health ${ }^{1}$. These problems are the beginning of a process of cognitive loss that can lead to dementia, ${ }^{4}$ where the cognitive deficit is more significant and the losses of autonomy and independence are greater. ${ }^{5}$

Among the main cognitive problems are highlighted and dementias. Mild cognitive impairment is defined as a disorder characterized by a recent cognitive decline perceived by the individual or the family itself to a degree beyond that expected for age or schooling and confirmed by a cognitive score that does not yet cause significant functional impairment. ${ }^{6}$ Dementia is characterized by the global and progressive loss of cognitive functions, with significant impairment of memory, learning, language, orientation and executive functions and is considered the main cause of dependence and disability among the elderly. ${ }^{7}$

The main risk factors for cognitive problems are low level of schooling and socioeconomic, hearing loss, systemic arterial hypertension, obesity, smoking, depression, physical inactivity, diabetes, atherosclerosis, no work activities, ${ }^{8}$ social isolationm ${ }^{9}$ low cognitive activity, being female, being single, making use of polymedication, using benzodiazepines, ${ }^{10}$ genetics (family history with first degree relative, presence of apolipoprotein E), inadequate diet (consumption of fats, fried foods, excess sugars and salt, and low consumption of fruits and vegetables), ${ }^{2}$ stress, low resilience, sadness, poor sleep pattern ${ }^{11}$ and low health perception, low birth weight. ${ }^{12}$

Thus, greater care is needed in relation to the cognitive function of the elderly, and it is important to stimulate this population with intervention practices. ${ }^{13}$ There are several forms of cognitive stimulation such as disease control, healthy diet, non-use of tobacco and alcohol abuse ${ }^{2,11}$ use of medicines, support groups, family care, intellectual work (readings, crossword puzzles, writing and puzzles), ${ }^{14}$ non-invasive brain stimulation, ${ }^{13}$ exergames $^{3}$, internet use and regular physical activity. ${ }^{2,11}$ Of these, the use of computers and the practice of physical activities have proved to be good therapeutic alternatives for maintenance, stimulation, and/or rehabilitation of cognitive function. ${ }^{15}$

The use of computers is associated with the reduction and reversal of several cognitive deficits. ${ }^{15,16}$ Longitudinal population survey of Krug, d' Orsi\&Xavier ${ }^{17}$ with 1,705 elderly interviewed in 20092010 and 1,197 in 2013-2014 showed that there was a significant association between maintaining internet and cognitive performance, with a greater chance of cognitive gain $(\mathrm{OR}=3.3,95 \% \mathrm{CI} 1.1-9.8)$ and lower cognitive loss $(\mathrm{OR}=0.39,95 \%$ CI $0.17-0.88)$ for the elderly who have been using the internet. Another longitudinal population study showed a stabilization and/or delay of cognitive decline resulting from the daily use of computers and the internet, both in middle-aged individuals and in the elderly, especially among those with lower cognitive capacity. ${ }^{18}$

However, the controlled intervention research of Krug et al. ${ }^{19}$ with 293 elderly showed that elderly people who participated in a Cognitive Cooperation Group based on Internet use (20 sessions of 1.5 hours each) had improvement of $24.39 \%(95 \% \mathrm{CI}=14.86 / 33.91)$ in cognitive function in relation to those who did not participate in the program. In addition, internet use can promote socialization through greater family ties and friends, new friendships, greater participation 
and cooperation in society, ${ }^{20}$ thus integrating this elderly into modern society and increasing the self-esteem of this population. ${ }^{15}$

The practice of physical activities can also be considered a good way of rehabilitating cognitive function ${ }^{21}$, because it improves attention, memory, executive function, increases oxygen transport to the brain, synthesis and degradation of neurotransmitters, improves response time and represses the decline of cardiovascular function associated with cognitive decline..$^{1,15}$ Meta-analysis study of Blondell, Hammersley-Mather e Veerman ${ }^{22}$ analyzed 46 studies on physical activity and cognitive decline/dementia, and found that people with a higher level of physical activity had a lower risk of cognitive decline $(\mathrm{RR}=0.65,95 \% \mathrm{CI} 0.55-0.76)$, and dementia $(\mathrm{RR}=0.86,95 \% \mathrm{CI} 0.76-$ $0.97)$ when compared to those with lower levels of physical activity. Diamond \&Ling ${ }^{11}$ have shown in their systematic review with 84 studies that the longer the weekly practice time of better physical activities are the cognitive outcomes, where 5-7days and 40minutes per session are more beneficial in cognitive function when compared to lower intensities, however, any intensity is beneficial. In addition, when checking the type of physical activity the authors find that walking and / or running with some company or group are the most effective.

The improvement of cognitive function caused by the practice of regular physical activities is due to the influence of the improvement of cardiovascular health (increased production of serotonin, dopamine and noradrenaline) $;{ }^{15}$ the reduction of low-grade systemic inflammation and the activation of antioxidant pathways that attenuate the impact of oxidative stress on the brain; ${ }^{23}$ and by the increase of neurotrophins and the volume of gray matter in the prefrontal area of the brain. ${ }^{11}$

In this sense, the use of computers and the practice of physical activities together can have a strong impact in the prevention, stimulation and treatment of cognitive problems. However, currently in Brazil, there is no specific internet access policy for the elderly, and universities exclusively through extension projects offer these types of programs. In this sense, at the University of the Far South Catarinense (UNISUL Tubarão and Palhoça), in the State University of São Paulo (UNIFESP) and the Federal University of Santa Catarina (UFSC) are already being offered jointly the practice of physical activities and the use of computers as a form of cognitive stimulation for the elderly. ${ }^{24}$

Based on the positive results of the extension and research programs of these universities, ${ }^{24}$ the low level of physical activity $(77.2 \%$ are physically inactive at leisure $)^{25}$ and the great digital exclusion ( $81 \%$ of the elderly do not use computers) of Brazilian elderly, ${ }^{26}$ this study had as objective to explain the protocol of the program of cognitive stimulation of the University of Cruz Alta (UNICRUZ).

\section{History of the UNICRUZ cognitive stimulation program}

UNICRUZ's cognitive stimulation program emerged in 2011, initially as a Digital Inclusion Project for senior citizens. This project was thought due to the great technological advances of the present time that have repercussions on the quality of life and the longevity of the people. The use of technologies created a new way of obtaining information, reasoning, leisure and socialization, but also generated a new form of exclusion, digital exclusion. Victims of this prejudice, elderly people, due to inaccessibility and limitations imposed by age, cannot keep up with the technological advances that are exposed daily. However, considering that the elderly are people who cannot be excluded from society and are entitled to the benefits of access to information and communication technology resources, he thought about this project.

For this reason the Digital Inclusion Project was developed in the third age with the objective of contributing to the socialization of the elderly, bringing digital knowledge to those who did not have access to it, so that they can become protagonists of these new social knowledge. With the implementation of the project, it sought to democratize access to the media and communication, generating opportunities for socialization, interaction and integration in today's society; optimize the use of technological resources of information and communication to collaborate in the production and socialization of knowledge; use digital technologies as a tool in the pursuit of citizenship; encourage the technology-enabled population to obtain better living conditions; to disseminate an information and knowledge society and to promote activities that allow the community a more agile incorporation of this new concept; to help the target public in communication with children, grandchildren and distant relatives, so that they can keep abreast with what is happening in the world, moments of leisure and to socialize and provide integration between university and community.

The target audience for the project is the community of Cruz Alta/ Brazil in general and other neighboring cities. Approximately 210 people 60 years of age or older have participated in the project.

As of 2018, in addition to the use of computers, the practice of walking was inserted in the project by means of a partnership between the courses of Computer Science and Bachelor of Physical Education being financed by PIBIC/CNPq/UNICRUZ and PIBIC-EM/CNPq/ UNICRUZ and having the support of the Post-Graduate Program in Integral Health Care. Entries in the workshops take place through the homepage created for the project. Becoming the Cognitive Stimulation Program of UNICRUZ.

This program complies with all ethical principles (Resolution 196 of the National Health Council) and was approved by the Ethics Committee on Human Research at UNICRUZ (CAEE 02968818.0.0000.5322).

\section{The UNICRUZ cognitive stimulation program}

The main objective of the program is to prevent, stabilize and/ or delay the evolution of cognitive problems, as well as increase the participation of these elderly people in the modern world through the use of internet and increase the level of physical activity and physical fitness of participants. There are usually 18 semester meetings held once or twice a week. The use of computers occurs in computer labs and the walk in the athletic track or in the multi-sport gym (on rainy and cold days) of UNICRUZ. Firstly in each meeting the elderly use computers for about 45 minutes and then the walk for 45 minutes.

The use of computers is based on the themes introduction to computer science, use of Windows, Word, Power Point, Internet browsers and MSN, e-mail management, research and social media, as well as typing and drawing programs.

The walk (duration of 30 minutes) is preceded by stretches for thelarge muscle groups (duration of five minutes and 30seconds for each activity). At the end the stretches are repeated and a conversation 
is held about the activities of the day (duration of 10minutes). All the activities are elaborated and taught by undergraduate scholarship students and volunteers of the baccalaureate and Computing Physical Education courses. In all, there are five scholarship holders, including a PIBIC/CNPq scholarship holder of the baccalaureate degree in Physical Education, a PIBIC-EM/CNPq scholarship holder, a PIBEX grant holder and two volunteers from the Computer Science course, besides of a Post Graduate in Integral Health Care academic, all from UNICRUZ.

At the beginning and end of each academic semester, the evaluation instruments are applied in face-to-face (individual) interviews in a separate room. The instruments are as follows:

a. Diagnostic card to identify gender, age, marital status, schooling in years of study, health history (hypertension, diabetes, hypothyroidism, dyslipidemia, metabolic syndrome, depression, stroke, transient ischemic attack, acute myocardial infarction) number of diagnoses, chronic pain, postural problems, sensorial changes, presence of motor problems in the upper limbs, use of tobacco and alcohol;

b. Mini Mental State Examination (MMSE), which assesses cognitive ability. In Brazil, this questionnaire was translated and validated by Bertolucci et al., ${ }^{27}$ previously used in population studies with the elderly and containing 30 questions about temporal and spatial orientation, fixation memory, evocation, attention, calculation, and language;

c. Brazilian Questionnaire on Multidimensional Functional Evaluation (BOMFAQ/OARS), which assesses functional disability or the performance of daily life activities validated in Brazil. It is composed of 15 questions about activities of daily 3 . living to assess functional capacity; ${ }^{28}$

d. The International Physical Activity Questionnaire (IPAQ) - a long form, a normal week, adapted for the elderly, ${ }^{29}$ which assesses the level of physical activity of the elderly. This is an instrument that allows estimating the weekly energy expenditure of physical activities related to work, leisure, transportation, domestic tasks, and in the sitting position, with moderate or vigorous intensity, for 10 continuous minutes in a normal week.

e. Six-Minute Walk Test (TC6), which evaluates respiratory muscle resistance. The test consists of walking (the participant cannot run) as far as possible in six minutes in a predetermined area. ${ }^{30}$

f. Body Mass Index which is the division of body weight $(\mathrm{kg})$ by height $(\mathrm{cm})$ squared.

\section{Contributions and expected results}

It is expected that UNICRUZ's cognitive stimulation program can prevent, ameliorate or reduce the cognitive problems of its participants both through participation in computer use ${ }^{19,24}$ and through the practice of activities physical. ${ }^{21}$ Through the use of computers it is hoped that the elderly can also increase their digital inclusion, an indispensable process of the modern world today, thus increasing their socialization, self-esteem, independence, as well as greater knowledge about health and physical activity. ${ }^{21}$ Another important point is that through the use of computers and internet the elderly can learn other important technologies such as the use of cell phones, check banks ATMs in person and via the internet, use of email and social networks. ${ }^{31}$
Through regular walking practice, the study participants are expected to increase their level of physical activity and consequently their physical fitness ${ }^{32,33}$ In this sense, the cognitive rehabilitation program will be very beneficial for the general health of the surveyed elderly.

\section{Conclusion}

It is concluded that cognitive rehabilitation programs for the elderly can bring many health benefits to them and that, in this sense, such actions should be encouraged, not only in the context of university extension, but also in public health, considering that these behaviors (physical activity and use of computers) can be effectively introduced in public policies for the elderly, being reproduced in Family Health Strategies, Community Councils, Elderly Groups, Nursing Homes and in many other places

\section{Acknowledgments}

None.

\section{Conflicts of interest}

The authors declare no conflicts of interest.

\section{References}

- American College of Sports Medicine. Exercise and Physical Activity for Older Adults. Med Sci Sports Exerc. 2009;41(7):1510-1530.

2. Nevalainen N, Riklund K, Andersson M, et al. COBRA: A prospective multimodal imaging study of dopamine, brain structure and function, and cognition. Brain Res. 2015;16:83-103.

3. Bleakley CM, Charles D, Porter-Armstrong A, et al. Gaming for health: a systematic review of the physical and cognitive effects of interactive computer games in older adults. J Applied Gerontol. 2015;34(3):166-189.

4. Radanovic M, Stella F, Forlenza OV. Mild Cognitive Impairment. Rev Med. 2015;94(3):162-168.

5. Fagundes TA, Gomes Pereira DA, Penido Bueno KM, et al. Functional disability of elderly with dementia. Brazilian Notebooks of Occupational Therapy. 2017;25(1):159-169.

6. Farias AMN. Cognitive Stimulation in sedentary elderly with Mild Cognitive Disorder. 2018. Dissertation (Master in Gerontology) - Stricto Sensu Graduate Program in Gerontology. Brasilia, Brazil: Catholic University of Brasilia; 2018.

7. World Health Organization (WHO). Dementia: a public health priority Geneva: World Health Organization; 2012. p. 112

8. Wang HX, MacDonald SW, Dekhtyar S, et al. Association of lifelong exposure to cognitive reserve-enhancing factors with dementia risk: A community-based cohort study. PLoS Med. 2017;14(3):e1002251.

9. Baloyannis SJ. Is Alzheimer's disease an existential fragmentation or an imprisonment of mind? J Neurol Stroke. 2019;9(3):155-157.

10. Williams J, Plassman BL, Burke J, et al. Preventing Alzheimer's disease and cognitive decline. Health. 2010;193:1-727.

11. Diamond A, Ling DS. Conclusions about interventions, programs, and approaches forimproving executive functions that appear justified and those that,despite much hype, do not. Dev Cogn Neurosci. 2016;18:34-48.

12. Garcia PY, Roussel M, Bugnicourt JM, et al. Cognitive Impairment and Dementia After Intracerebral Hemorrhage: A Cross-sectional Study of a Hospital-based Series. J Stroke Cerebr Dis. 2013;22(1):80-86. 
13. Rodrigues ITRM. Transcranial Direct current stimulation in Dementia: a possible breakthrought. J Neurol Stroke. 2019;9(1):26-27.

14. Santana RF, Alexandrino SA, Soares ST, et al. Cognitive Stimulation Workshops for the elderly with subjective memory and mood complaints. Rev Enf UFSM. 2018;8(4):716-730.

15. Barnes DE, Santos-Modesitt W, Poelke G, et al. The Mental Activity and eXercise (MAX) Trial. JAMA Int Medicine. 2013;173(9):797-804.

16. d'Orsi E, Xavier AJ, Steptoe A, et al. Socio demographic and lifestyle factors related to instrumental activities of daily living dynamics: results from the English Longitudinal Study of Ageing. J Am Geriatrics Soc. 2014;62(9):1630-1639.

17. d' Orsi E, Rosso Krug R, Xavier AJ. Association between internet use and cognitive function in the elderly, longitudinal population study Epifloripa Elderly?. Rev Bras Epidemiol. 2019;22:1-12.

18. Xavier AJ, d'Orsi E, de Oliveira CM, et al. English Longitudinal Study of Ageing (ELSA): can internet/email use reduce cognitive decline? $J$ Gerontol A Biol Sci Med Sci. 2014;69(9):1117-1121.

19. Krug RR, Silva AQAD, Schneider IJC, et al. Cognitive Cooperation Groups mediated by computers and internet present significant improvement of cognitive status in older adults with memory complaints: a controlled prospective study. Arq Neuro-Psiq. 2017;75(4):228-233.

20. Xavier AJ1, d'Orsi E, Wardle J, et al. Internet use and cancer-preventive behaviors in older adults: findings from a longitudinal cohort study. Cancer Epidemiol Biom Prev. 2013;22(11):2066-2074.

21. Krug RR, Henrique da SL, Lucas Wilibinger de, et al. Importância da atividade física na função cognitiva de idosos. University Management Magazine. 2018;10:1-8.

22. Blondell SJ, Hammersley-Mather R, Veerman JL. Does physical activity prevent cognitive decline and dementia?: A systematic review and metaanalysis of longitudinal studies. BMC Public Health. 2014;14:510.

23. Lamont AJ, Mortby ME, Anstey KJ, et al. Using sulcal and gyrsal measures of brain structure to investigation of an activity lifestyle. NeuroImage. 2014;91(1):353-359.
24. Krug RR, Mortean Ono L, Quialheiro A, et al. Stimulation and rehabilitation cognitive program: Oficina da Lembrança. Rev Bras Ativ Fís \& Saúde. 2015;20(5):534-540.

25. Vigitel. Ministry of Health. Vigilitel Brazil 2014: surveillance of risk factors and protection for chronic diseases by telephone survey. Ministry of Health, Health Surveillance Secretariat, Secretariat for Strategic and Participatory Management. Brasília, Brazil: Ministry of Health; 2015.

26. Center for Studies on Information and Communication Technologies (Cetic.br. Research on the Use of Information and Communication Technologies in Brazil: ICT Households and ICT Enterprises 2014. São Paulo, Brazil: Brazilian Internet Steering Committee (CGI.br); 2014.

27. Bertolucci PH, Brucki SM, Campacci SR, et al. O mini-exame do estado mental em uma população geral: impacto da escolaridade. Arq Neuropsiquiatr. 1994;52(1):1-7.

28. Ramos LR. Determinants of healthy aging in elderly residents of an urban center : Projeto Epidoso, São Paulo. Public Health. 2003;19(3):793-798.

29. Mazo GZ, Benedetti TRB. Adaptation of the international physical activity questionnaire for the elderly. Rev Bras Cineantropom Performance Hum. 2010;12(6):480-484.

30. Rikli R, Jones C. Development and Validation of a Functional Fitness Test for Community-Residing Older Adults. J Aging Phys Act. 1999;7(2):129 161.

31. Kachar, V. Aging and prospects for digital inclusion. Kairós. 2010;13(2):131-147.

32. Marchesan M, Rosso Krug R de, Rodrigues da Conceição JC, et al. Contribuições da caminhada como atividade física de lazer para idosos. Journal of the Interdisciplinary Postgraduate Program in Leisure Studies. 2011;14(4):1-29.

33. Marchesan M, Krug R, Monego E, et al. The Community Council: Promoting physical exercise for the elderly from Florianópolis - SC. Rev Bras Ativ Video \& Saudi. 2015;20(1):93-99. 